\title{
Dynamic Modeling Method of Transmission Gear System for Pure Electric Vehicle
}

\author{
Yulong $\mathrm{LEI}^{1}$, Xiaoxin $\mathrm{GANG}^{2}$, Yao $\mathrm{FU}^{3,{ }^{*}}$, Jianlong $\mathrm{HU}^{4}$, Bo YAN ${ }^{5}$ \\ ${ }^{1-5}$ State Key Laboratory of Automotive Simulation and Control, Jilin University, Changchun, \\ 130025, China \\ *Email:fuy.jlu@163.com
}

Keywords: Transmission Gear System, Dynamic Modeling.

\begin{abstract}
This paper combines the advantages of the finite element method and lumped parameters to build the dynamic model of gear system. The gear is regarded as concentrated mass while the axis is considered as an elastic beam element and the quality of the bearing unit is ignored. Each element is assembled by finite element method to establish full dynamic model. Compared with the method of calculating dynamic response of gear transmission system by finite element software, this method has high computational efficiency. In this way, it is convenient to do the subsequent dynamic analysis.
\end{abstract}

\section{Introduction}

At present, many people have studied the meshing dynamic model of single stage gear pair. The dynamic model of single gear pair simplifies the gear system and cancels the detailed modeling of shaft and bearing. In this way, they can only get very little dynamic information and can hardly get all the characteristics of gear system dynamics [1]. Most of the gear dynamic models are relevant to the reducer. However, the research on the transmission with many shifts and multiple gears is less. Based on the generalized finite element method, the dynamic model of the universal parallel shaft gear transmission system is given by passage [2]. But it only gives out one example of single stage gear pair. As for the transmission system with three axles, it is made up of multistage gear pair and many shifts which can be chosen. So its structure is quite different from the ordinary reducer. This paper gives out a description of the modeling process of a three axis transmission.

\section{Dynamic modeling method for the main parts of the transmission}

This chapter takes an AMT of a pure electric bus as the research object. This transmission has three axles and its basic structure is shown in Figure 1. Gear transmission system contains 4 gear pairs and achieves 4 shifts. The basic parameters and speed ratios are shown in Table 1.

In order to simplify the modeling steps, we only consider the main factors of gear system and ignore the factors that have little influence on the gear dynamic characteristics. We make the following assumptions about the gear system.

(1) The gear is regarded as the concentrated mass and its mass is concentrated in the center of mass. The interaction between gears is simplified to a spring of which the stiffness is variable. Stiffness of spring equals to time-varying meshing stiffness of gear pair Ignore the backlash and friction of the gears. The influences of error and meshing impact are not considered.

(2)Each axle is dispersed and simplified as a beam element.

(3)The mass of bearing is not considered. The bearing is simplified as a spring of three directions which has two radial stiffness and an axial stiffness. Ignore the angle stiffness and coupling stiffness of the bearing.

(4)Ignore the effects of gravity on gears, bearings, shafts and other components.

(5)Ignore the effect of gear pairs which are not involved in the transmission of power within the transmission. 


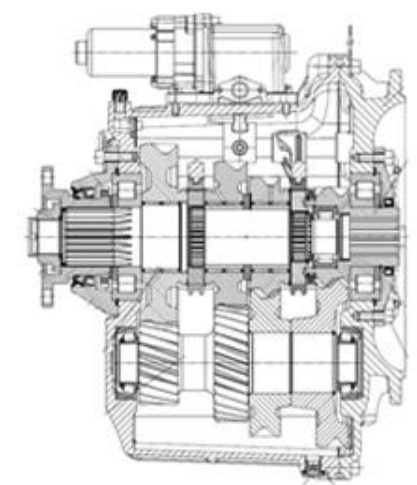

Fig.1. Basic Structure of the AMT

Table 1 Gear Parameters of the Transmission

\begin{tabular}{cccccc}
\hline Shifts & $\begin{array}{c}\text { Tooth } \\
\text { Number of } \\
\text { Constant } \\
\text { Mesh } \\
\text { Driving } \\
\text { Gear }\end{array}$ & $\begin{array}{c}\text { Tooth } \\
\text { Number of } \\
\text { Constant } \\
\text { Mesh } \\
\text { Driven Gear }\end{array}$ & $\begin{array}{c}\text { Tooth } \\
\text { Number of } \\
\text { Driven Gear } \\
\text { on } \\
\text { Intermediat } \\
\text { e Shaft }\end{array}$ & $\begin{array}{c}\text { Tooth } \\
\text { Number of } \\
\text { Output } \\
\text { Shaft }\end{array}$ & Speed Ratio \\
\hline 1 & 24 & 43 & 19 & 47 & 4.432 \\
2 & & & 29 & 39 & 2.41 \\
3 & - & - & - & 31 & 1.462 \\
4 & & & - & - & 1 \\
R & Reverse the motor to get reverse gear & \\
\hline
\end{tabular}

Three shaft transmission system is mainly composed of an input shaft, intermediate shaft and output shaft, gears, bearings and gear box. Mass of the gear system distributes continuously, so its dynamic model is difficult to be built. Each axle should be dispersed and simplified as a beam element to build the dynamic model. The gear is regarded as concentrated mass and we use lumped mass method to build the dynamic model of the gear pairs. Finally, the stiffness, mass and damping matrix of each dynamic equation are assembled according to the finite element method. In this way, we get the dynamic model of the whole gear transmission system except the gearbox. The gear transmission system is transformed from a continuum and infinite degree of freedom to a finite degree of freedom which is easy to be modeled, solved and analyzed. Figure 2 shows the basic structure of the transmission gear system after discretization. The actual discretization scheme, the number of nodes and units are determined by the actual structure and calculation accuracy requirements of the gear transmission system.

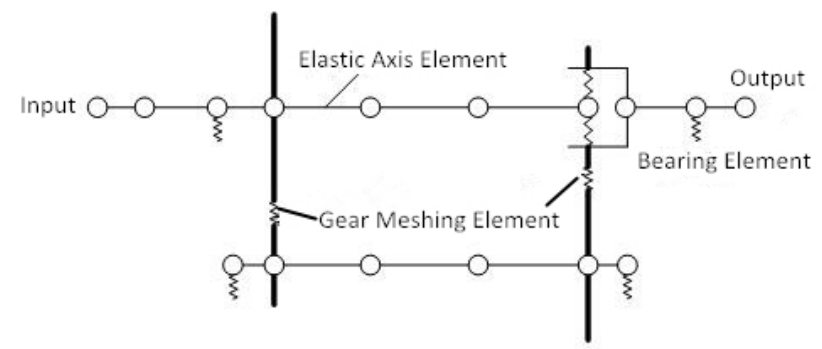

Fig.2. Discrete Model of Gear Transmission System

\subsection{Dynamic modeling of gear meshing unit}

In order to establish the dynamic model of gear meshing unit, we should analyze the force of the gear meshing process first. Figure 3 is the schematic diagram of force analysis of helical gears. 


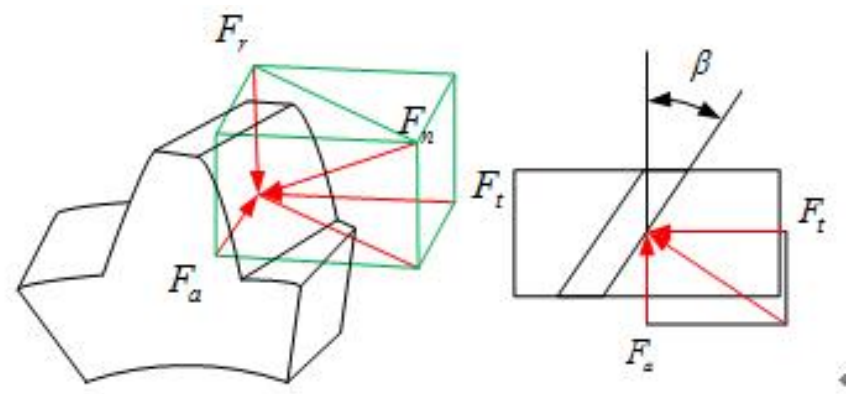

Fig.3. Schematic Diagram of Force Analysis of Helical Gears

Ignore the friction on the surfaces of gear pairs. Due to the normal pressure angle $\alpha_{n}$ of gear tooth surface and the helix angle $\beta$ when the driving gear is subjected to a

torque of magnitude $\mathrm{T}$, there will be a normal force $F_{n}$ perpendicular to the tooth surface in the meshing plane which is tangent to the base cylinder. $F_{n}$ can be divided into radial force $F_{r}$, axial force $F_{a}$ and circumferential force $F_{t}$. The relationship between the three forces and normal force $F_{n}$ is shown in Figure 3. The relationship between radial force, axial force and circumferential force is,

$$
\begin{aligned}
F_{t} & =\frac{2 T}{d} \\
F_{r} & =\frac{F_{t} \tan \alpha_{n}}{\cos \beta} \\
F_{a} & =F_{t} \tan \beta \\
F_{n} & =\frac{F_{t}}{\cos \alpha_{n} \cos \beta}
\end{aligned}
$$

According to the force characteristics of helical gear pair, we project the normal force of the helical gear pair into three directions of the space coordinate system and get the force in the $\mathrm{X}$ direction $F_{n} \sin \beta \cos \alpha_{n}$ (axial force), the force in the $\mathrm{Y}$ direction $F_{n} \cos \beta \cos \alpha_{n}$ (circumferential force) and the force in the $\mathrm{Z}$ direction

$F_{n} \sin \alpha_{n}$ (radial force).

For the general three shaft transmission, the phase angle between mutually engaged gear pairs is fixed because the three axes are arranged in the same plane. In the modeling process, if we choose a suitable global coordinate system, we can ignore the influence of phase angle. The driving gear and driven gear are regarded as concentrated mass respectively to analyze the six degrees of freedom of each gear. According to Newton's second law, the dynamic equations of meshing gear pair can be listed as below,

$$
\left\{\begin{array}{l}
m_{p} \ddot{x}_{p}+\left(k_{m} \delta+c_{m} \dot{\delta}\right) \sin \beta \cos \alpha_{n}=0 \\
m_{p} \ddot{y}_{p}+\left(k_{m} \delta+c_{m} \dot{\delta}\right) \cos \beta_{n} \cos \alpha_{n}=0 \\
m_{p} \ddot{y}_{p}+\left(k_{m} \delta+c_{m} \dot{\delta}\right) \sin \alpha_{n}=0 \\
I_{x p} \ddot{\theta}_{p}+\left(k_{m} \delta+c_{m} \dot{\delta}\right) \mathrm{r}_{p} \cos \beta \cos \alpha_{n}=0 \\
I_{y p} \ddot{\varphi}_{p}+\left(k_{m} \delta+c_{m} \dot{\delta}\right) \mathrm{r}_{p} \sin \beta \cos \alpha=0 \\
I_{z p} \ddot{\psi}_{p}-\left(k_{m} \delta+c_{m} \dot{\delta}\right) \mathrm{r}_{p} \sin \alpha_{n}=0 \\
m_{g} \ddot{x}_{g}-\left(k_{m} \delta+c_{m} \dot{\delta}\right) \sin \beta \cos \alpha_{n}=0 \\
m_{g} \ddot{y}_{g}-\left(k_{m} \delta+c_{m} \dot{\delta}\right) \cos \beta_{n} \cos \alpha_{n}=0 \\
m_{g} \ddot{y}_{g}-\left(k_{m} \delta+c_{m} \dot{\delta}\right) \sin \alpha_{n}=0 \\
I_{x g} \ddot{\theta}_{g}-\left(k_{m} \delta+c_{m} \dot{\delta}\right) \mathrm{r}_{g} \cos \beta \cos \alpha_{n}=0 \\
I_{y g} \ddot{\varphi}_{g}-\left(k_{m} \delta+c_{m} \dot{\delta}\right) \mathrm{r}_{g} \sin \beta \cos \alpha=0 \\
I_{z g} \ddot{\psi}_{g}+\left(k_{m} \delta+c_{m} \dot{\delta}\right) \mathrm{r}_{g} \sin \alpha_{n}=0
\end{array}\right.
$$


In the type(5): $m_{p}$ is the mass of the driving gear, $m_{g}$ is the mass of the driven gear $I_{x p}, I_{y p}, I_{z p}$ are the inertia of driving gear around the X, Y, Z axis $I_{x g}, I_{y g}, I_{z g}$ are the inertia of driven gear around the $\mathrm{X}, \mathrm{Y}, \mathrm{Z}$ axis $k_{m}$ is the meshing stiffness of gear pairs along the normal plane. $c_{m}$ is the damping coefficient of gear pair along the normal plane $r_{p}$ and $r_{g}$ are the pitch radius of driving gear and driven gear $\delta$ stands for projection of the vibration displacement of each direction in the gear meshing line.

Deformation of driving gear and driven gear along the meshing line direction is

$$
\delta=V q
$$

In the type(6): $q=\left\{x_{p}, y_{p}, z_{p}, \theta_{p}, \varphi_{p}, \psi_{p}, x_{g}, y_{g}, z_{g}, \theta_{g}, \varphi_{g}, \psi_{g}\right\}^{T}$ It represents the displacement column vector when the driving gear and driven gear are engaged. $\theta, \varphi$ 、 $\psi$ represent the axial displacement of $\mathrm{X}, \mathrm{Y}, \mathrm{Z}$, respectively. $\mathrm{V}$ is the projection matrix of the vibration displacement of each direction in the gear meshing line. It can be obtained from the force analysis of helical gear. Formula for calculating damping coefficient matrix $c_{m}$ of gear pair is

$$
c_{m}=\frac{2 \zeta}{\sqrt{\bar{k}_{m} /\left(1 / m_{p}+1 / m_{g}\right)}}
$$

In the type(7): $\bar{k}_{m}$ is the average meshing stiffness. $\zeta$ is the damping ratio. Generally, its range is 0.03-0.17, this article takes 0.1 .

\subsection{Dynamic modeling of bearing element}

In order to simplify the calculation, we do not consider the variation of the stiffness with the load in the gear system dynamic analysis. Based on the estimated values in the existing article [3], the radial stiffness and axial stiffness of bearings are considered as constants. The mass of bearing is generally small. For the bearings which are directly connected with the gearbox in the three shaft transmission, one end of the outer ring of the bearing unit is regarded as fixed. At this point, the bearing dynamic equation can be expressed by the type(8):

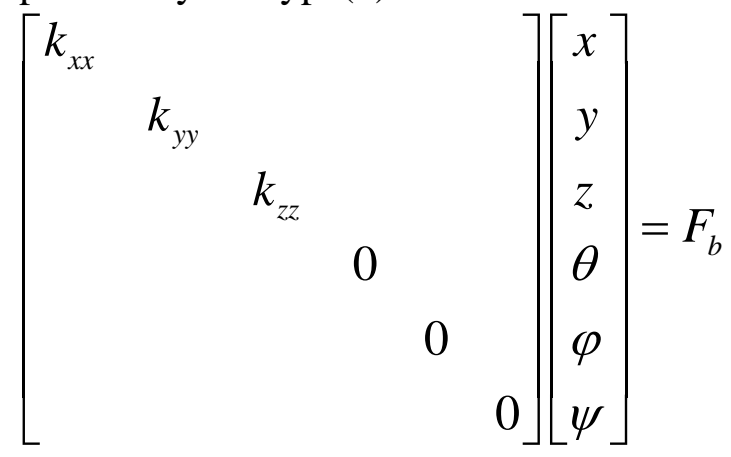

In the type(8): $k_{x x}$ is the axial stiffness of bearing $k_{y y}$ and $k_{z z}$ is the radial stiffness of bearing $F_{b}$ is the force acting on the bearing $\left[\begin{array}{llllll}x & y & z & \theta & \varphi & \psi\end{array}\right]^{\mathrm{T}}$ is translational and torsional deformation of six directions of bearing.

In the three shaft transmission, input shaft and output shaft are connected by bearing. The inner and outer rings of the bearing are respectively connected with the input shaft and the output shaft. The processing method of the stiffness matrix and the processing method of the bearing connected to gearbox are different. The deformation depends on the difference between the displacement and rotational displacement at both ends of the bearing node. When we establish the dynamic model of the bearing between the input shaft and the output shaft, it is necessary to consider the displacement changes of the bearings at both ends at the same time. The dynamic model of the bearing contains twelve freedoms. Its formula is 


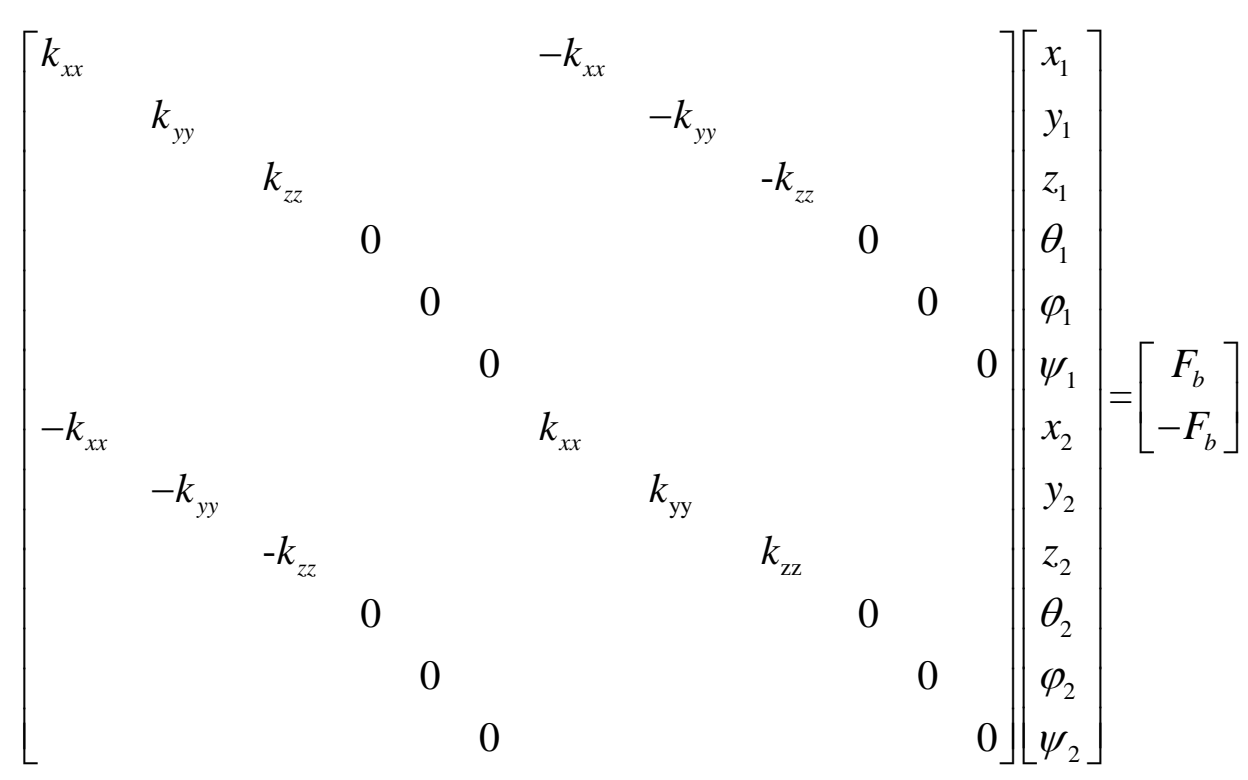

\subsection{Dynamic modeling of elastic shaft element}

In order to study the effect of shaft deformation on transmission dynamics characteristics in transmission dynamics model, the shaft is considered as an elastic body. We use finite element method to build the shaft model. Figure 4 shows the forces acting on the shaft element. The coordinates of the nodes on both ends of the shaft unit are respectively represented as $\left[x_{1}, y_{1}, z_{1}, \theta_{1}, \varphi_{1}, \psi_{1}, x_{2}, y_{2}, z_{2}, \theta_{2}, \varphi_{2}, \psi_{2}\right]$. The axial element is analyzed by using the spatial beam element theory. In this article, we use the classical Euler-Bernoulli beam element. According to the related knowledge of elastic mechanics, the stiffness matrix of Euler-Bernoulli beam element can be deduced. The stiffness matrix and mass matrix of Euler-Bernoulli are deduced in detail and the final results are given in article [4]. This article directly applies these results without pushover.
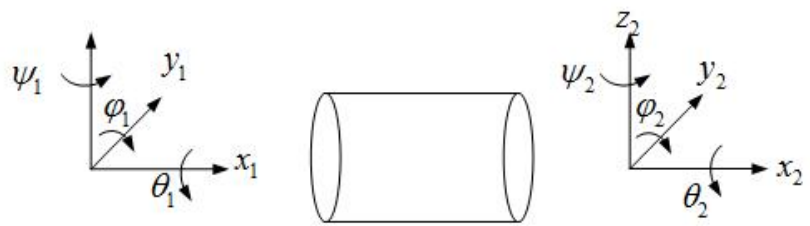

Fig.4. Force Sketch of the Elastic Axis

The damping of shaft element is treated by Rayleigh damping. Rayleigh damping is introduced in detail in article [5]. The formula for Rayleigh damping is

$$
C_{\text {shaft }}=\alpha M_{\text {shaft }}+\beta K_{\text {shaft }}
$$

In the type(10): $\alpha$ is the mass ratio coefficient $\beta$ is stiffness ratio coefficient. Rayleigh damping coefficient $\alpha$ and $\beta$ are mainly related to the damping ratio and the modal frequency of the structure. Article [6] gives the calculation method of $\alpha$ and $\beta$.

\section{Dynamic modeling of the transmission gear system}

According to the dynamic modeling method of each part and referring to the assembly method of stiffness matrix, damping matrix and mass matrix in finite element method, we can easily get the overall dynamic equation of gear transmission system.

$$
M \ddot{x}_{t}+C \dot{x}(t)+K(t) x(t)=F(t)
$$

In the type(11): $M$ is the system mass matrix, $C$ is the Total damping matrix of the system, $K(t)$ is the total stiffness matrix of the system $F(t)$ is the vector columns of node load.

Gear system dynamics modeling steps are as follows,

(1)Get parameters of the gear system, including shaft parameters, gear parameters, bearing 
parameters, material properties, etc.

(2)Pre-process of the gear system. Discretize the axis. Determine the number of node and element. Determine the shift to be calculated and the working gear pair. Determine the location of the gear pair and the bearing.

(3)Calculate the stiffness matrix, damping matrix and mass matrix of shaft element, bearing element and gear pair;

(4)Determine the working conditions, including input speed and input torque. Get the vector columns of the node load.

(5)Refer to the finite element method to assemble the stiffness matrix, damping matrix and mass matrix of each element.

\section{Establishment and solution of dynamic equation}

The dynamic equation group of gear system is a multidimensional nonlinear differential equation system with time-varying coefficient matrix. Considering the complexity of dynamic equations, if we use the analytic method, it is very difficult to solve the equation group. So we use numerical method to solve the dynamic equations. Common numerical solutions for solving nonlinear differential equations are Runge-Kutta method, backward Euler method, Newmar-beta method.These numerical methods have their own advantages and disadvantages.

There is a Runge-Kutta method toolbox in MATLAB software. The algorithm can change the computation step adaptively, but the convergence speed is slow and the computational resources are consumed. Variable step size algorithm is not conducive to the calculation results in frequency domain analysis. The backward Euler method has good stability, fast calculation speed, but low precision, and needs to reduce the step to make up the problem of low precision. The advantage of Newmar- beta method is that when the algorithm parameter is reasonable, the calculation result is unconditionally stable. The results obtained by this algorithm are independent of step length, and the calculation precision is high. According to the advantages and disadvantages of several algorithms, taking the specific conditions of the listed dynamic equations into consideration, we use Newmar- beta method to solve the dynamic equations. The dynamic response of the gear transmission system is obtained, and the frequency domain response of the bearing unit is obtained by Fast Fourier Transform (FFT) which transforms the result from time domain to frequency domain .

The following is a brief introduction of Newmark- beta method.

For the differential equation,

$$
M \ddot{x}+C \dot{x}+K x=F
$$

Taylor expansion of $x_{t+\Delta t}$ at $t$ moment,

$$
x_{t+\Delta t}=x_{t}+\dot{x}_{t} \Delta t+\frac{\ddot{x}(\xi)}{2} \Delta t^{2}
$$

In the formula above, $\xi \in[t, t+\Delta t]$.

$$
\ddot{x}(\xi)=(1-2 \alpha) \ddot{x}_{t}+2 \alpha \ddot{x}_{t+\Delta t}
$$

Use the type(13) and type(14),we can get

$$
\ddot{x}_{t+\Delta t}=\frac{1}{\alpha \Delta t^{2}}\left(x_{t+\Delta t}-x_{t}\right)-\frac{1}{\alpha \Delta t} \dot{x}_{t}-\left(\frac{1}{2 \alpha}-1\right) \ddot{x}_{t}
$$

In the same way, Taylor expansion of $\dot{x}_{t+\Delta t}$ and we can get

$$
\begin{gathered}
\dot{x}_{t+\Delta t}=\dot{x}_{t}+\ddot{x}(\xi) \Delta t \\
\ddot{x}(\xi)=(1-\beta) \ddot{x}_{t}+\beta \ddot{x}_{t+\Delta t}
\end{gathered}
$$

Use the type(16) and the type(17),we can get

$$
\dot{x}_{t+\Delta t}=\dot{x}_{t}+(1-\beta) \Delta t \ddot{x}_{t}+\beta \Delta t \ddot{x}_{t+\Delta t}
$$


The specific steps of Newmar- beta algorithm are as follows,

(1) For the given $x_{0}$ and $\dot{x}_{0}$, use the type(12) to work out $\ddot{x}_{0}$,

$$
\ddot{x}_{0}=M^{-1}\left(\mathrm{~F}-K x_{0}-C \dot{x}_{0}\right)
$$

(2) Determine integral step size $\Delta t$, use the given algorithm parameters $\alpha$ 、 $\beta\left(\beta \geq 0.5, \alpha \geq 0.25(0.5+\beta)^{2}\right)$ to work out the integral constant

$$
A_{1}=\frac{1}{\alpha \Delta t^{2}}, A_{2}=\frac{\beta}{\alpha \Delta t}, A_{3}=\frac{1}{\alpha \Delta t}, A_{4}=\frac{1}{2 \alpha}-1, A_{5}=\frac{\Delta t}{2}\left(\frac{\beta}{\alpha}-2\right), A_{6}=\frac{\beta}{\alpha}-1
$$

(3) When we calculate $t+\Delta t$, we can deduce the equivalent stiffness matrix by using the mass matrix $M$, stiffness matrix $K$ and damping matrix $C$ of the dynamic equation,

$$
\bar{K}=K+A_{1} M+A_{2} C
$$

(4) Calculate the payload at the moment $t+\Delta t$,

$$
\bar{F}_{t+\Delta t}=F_{t+\Delta t}+\left[A_{1} x_{t}+A_{3} \dot{x}_{t}+A_{4} \ddot{x}_{t}\right] M+\left[A_{2} x_{t}+A_{6} \dot{x}_{t}+A_{5} \ddot{x}_{t}\right] C
$$

(5) Calculate the displacement, velocity and acceleration at the moment $t+\Delta t$,

$$
\begin{gathered}
x_{t+\Delta t}=\bar{K}^{-1} \bar{F}_{t+\Delta t} \\
\ddot{x}_{t+\Delta t}=A_{1}\left(x_{t+\Delta t}-x_{t}\right)-A_{3} \dot{x}_{t}-A_{4} \ddot{x}_{t} \\
\dot{x}_{t+\Delta t}=\dot{x}_{t}+(1-\beta) \Delta t \ddot{x}_{t}+\beta \Delta t \ddot{x}_{t+\Delta t}
\end{gathered}
$$

We can write programs in accordance with the above steps in the MATLAB software to solve the dynamical equations and analyze the dynamic response of each position of the gear system. The FFT function can be called directly in the MATLAB software. So it is easy to transform the result from time domain response to frequency domain response.

\section{Calculation method of each part}

\subsection{Calculation method of gear pair unit parameters}

When the input shaft speed is $1500 \mathrm{r} / \mathrm{min}$, according to the basic parameters of gear and the speed relation in table 2, the time-varying meshing stiffness of the constant meshing gear pair and the gear pairs of each shift can be calculated. The stiffness matrix of gear pair is calculated according to the dynamic modeling method of gear meshing unit described by 2.1.

The shape of gears is irregular, and its mass and inertia are very complex to be calculated. Since we already have a three-dimensional model of the gear transmission system, we can view the estimated values of inertia and mass of gears in the software by just giving the gear material attributes in 3D software. The geometric parameters and mass parameters of the constant meshing gear pair and the gear pair in the third shift obtained from the three-dimensional software are shown in table 3 . According to the parameters in the table, the mass matrix of the two gear pairs working in the third shift can be calculated. The mass matrix is used to establish the dynamic model of the gear pairs in the third shift.

Table 2 Geometric Parameters of Transmission Gears

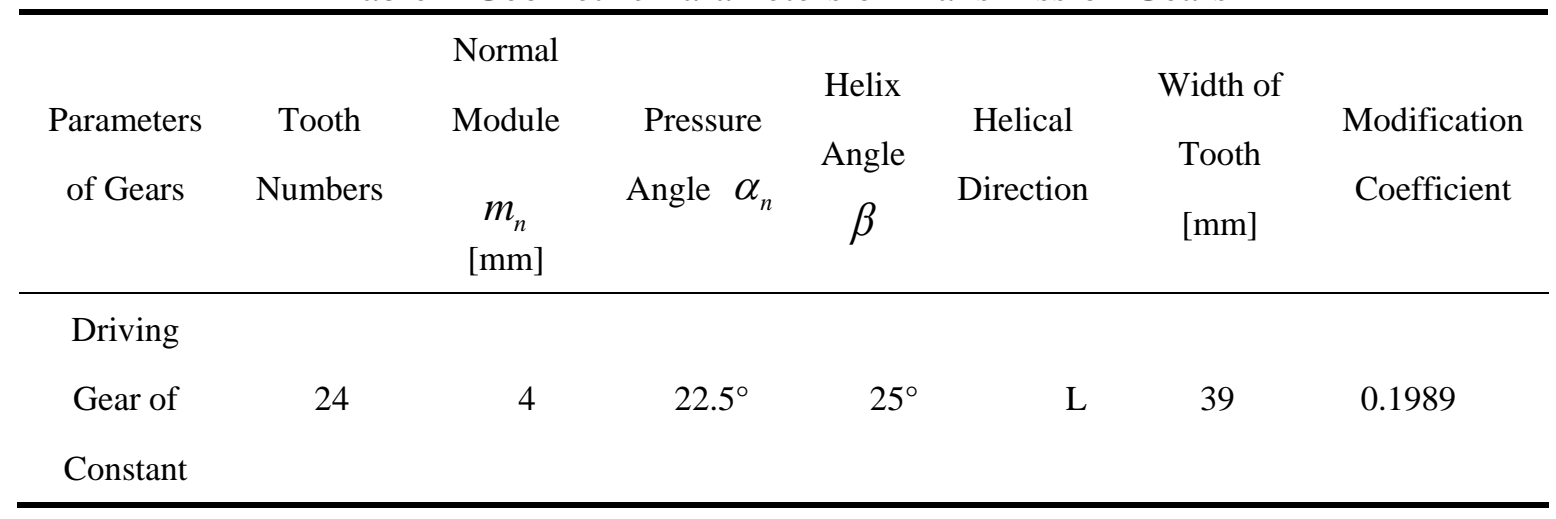




\begin{tabular}{|c|c|c|c|c|c|c|c|}
\hline \multicolumn{8}{|l|}{ Meshing } \\
\hline \multicolumn{8}{|l|}{ Driven Gear } \\
\hline of Constant & 43 & 4 & $22.5^{\circ}$ & $25^{\circ}$ & $\mathrm{R}$ & 37 & -0.162 \\
\hline \multicolumn{8}{|l|}{ Meshing } \\
\hline \multicolumn{8}{|l|}{ Driving } \\
\hline Gear of & 19 & 4.25 & $22.5^{\circ}$ & $19^{\circ}$ & $\mathrm{R}$ & 46 & 0.198 \\
\hline \multicolumn{8}{|l|}{ Shift 1} \\
\hline $\begin{array}{c}\text { Driven Gear } \\
\text { of Shift } 1\end{array}$ & 47 & 4.25 & $22.5^{\circ}$ & $19^{\circ}$ & $\mathrm{L}$ & 45 & -0.2755 \\
\hline \multicolumn{8}{|l|}{ Driving } \\
\hline Gear of & 29 & 4 & $22.5^{\circ}$ & $21^{\circ}$ & $\mathrm{R}$ & 40 & 0.39 \\
\hline \multicolumn{8}{|l|}{ Shift 2} \\
\hline $\begin{array}{c}\text { Driven Gear } \\
\text { of Shift } 2\end{array}$ & 39 & 4 & $22.5^{\circ}$ & $21^{\circ}$ & $\mathrm{L}$ & 38.5 & 0.2137 \\
\hline \multicolumn{8}{|l|}{ Driving } \\
\hline Gear of & 38 & 4 & $22.5^{\circ}$ & $22^{\circ}$ & $\mathrm{R}$ & 36.5 & -0.0364 \\
\hline \multicolumn{8}{|l|}{ Shift 3} \\
\hline $\begin{array}{c}\text { Driven Gear } \\
\text { of Shift } 3\end{array}$ & 31 & 4 & $22.5^{\circ}$ & $22^{\circ}$ & $\mathrm{L}$ & 36.5 & -0.17 \\
\hline
\end{tabular}

Table 3 Parameters of Gears in the Third Shift

\begin{tabular}{cccccccc}
\hline $\begin{array}{c}\text { Tooth } \\
\text { Numbers }\end{array}$ & $\begin{array}{c}\text { Pitch } \\
\text { Diameter } \\
{[\mathrm{m}]}\end{array}$ & $\begin{array}{c}\text { Hub } \\
\text { Diameter } \\
{[\mathrm{m}]}\end{array}$ & $\begin{array}{c}\text { Width of } \\
\text { Tooth } \\
{[\mathrm{m}]}\end{array}$ & $\begin{array}{c}\text { Area } \\
{\left[\mathrm{m}^{2}\right]}\end{array}$ & $\begin{array}{c}\text { Mass } \\
{[\mathrm{kg}]}\end{array}$ & $\begin{array}{c}\text { Rotary } \\
\text { Inertia 1 } \\
{\left[\mathrm{kg} \cdot \mathrm{m}^{2}\right]}\end{array}$ & $\begin{array}{c}\text { Rotary } \\
\text { Inertia 2 } \\
{\left[\mathrm{kg} \cdot \mathrm{m}^{2}\right]}\end{array}$ \\
\hline 24 & 0.096 & 0.072 & 0.039 & 0.003167 & 0.97690 & 0.003641 & 0.007034 \\
43 & 0.172 & 0.07 & 0.037 & 0.019387 & 5.67392 & 0.049562 & 0.09783 \\
38 & 0.152 & 0.072 & 0.0365 & 0.014074 & 4.06347 & 0.029188 & 0.057474 \\
31 & 0.124 & 0.083 & 0.0365 & 0.006666 & 1.92448 & 0.010926 & 0.021424 \\
\hline
\end{tabular}

\subsection{Calculation method of shaft unit parameter}

Discretize the input shaft, intermediate shaft and output shaft. The discrete gear system model is shown in Figure 5. The input shaft is divided into 5 segments, the intermediate shaft is divided into 11 segments and the output shaft is divided into 10 segments. The model consists of 32 nodes and 192 degrees of freedom. Torque input is at node1 and torque output is at node 20. Node 2, node 20, node 22, node 31 is for the bearing. Node 7 and node 8 are used for the input shaft and the output shaft connecting the inner and outer rings of the bearing. Node 4 and node 30 are used for constant meshing gear pairs. Node 24 and node 15 are used for the gear pair in the first shift. Node 27 and node 12 are used for the gear pair in the second shift. Node 29 and node 11 are used for the gear pair in the third shift.

According to the section 2, we can calculate the geometric parameters of each axis element, 
including the inner diameter of the shaft, outer diameter of the shaft, inertia, polar inertia and sectional area. According to the geometric parameters of shaft and the calculation method of the shaft elements in 2.3 section, we can obtain the mass matrix, stiffness matrix and damping matrix of the shaft.

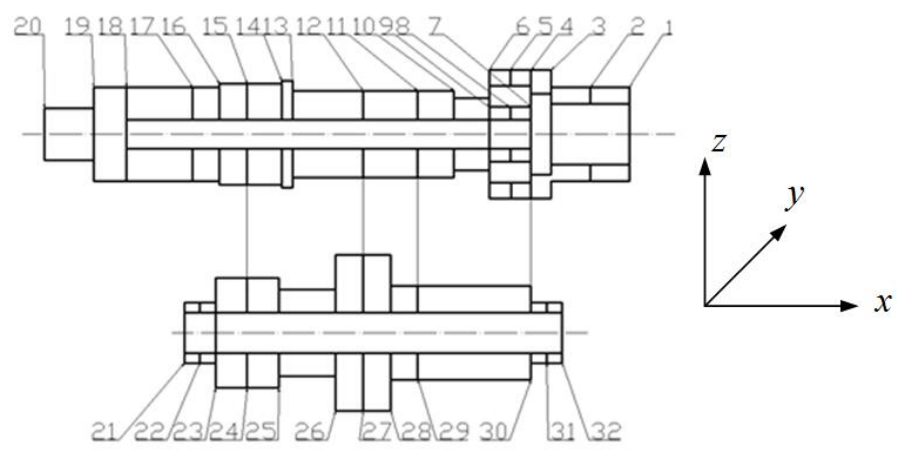

Fig.5. Discrete Model of the Shaft Segments

\subsection{Calculation method of the bearing unit parameter}

Table 4 gives the detailed parameters of each bearing. Bearing 1 is for the input shaft. Bearing 2 and bearing 3 are for the intermediate shaft. Bearing 4 is for the output shaft. Bearing 5 is used for connecting the input shaft and the output shaft. According to the parameters in Table 4 and the calculation method of bearing stiffness in the second chapter, we can get the axial stiffness and radial stiffness of the shaft element. Then, we can list the stiffness matrix of the bearing. In order to simplify the calculation, the bearing stiffness is not considered with the change of load. According to the estimated stress condition of the bearing seat, the axial stiffness and radial stiffness of the bearing are selected.

Table 4 the Parameter of the Bearings

\begin{tabular}{ccccc}
\hline Bearing & Bearing Designation & Numbers of Rolling Elements & $\begin{array}{c}\text { Contact Length of } \\
\text { Rolling Elements }\end{array}$ & Contact Angle \\
\hline 1 & NUP314R & 13 & 22 & - \\
2 & $32209 J R-1$ & 18 & 15.8 & $15^{\circ}$ \\
3 & $32209 J R-1$ & 18 & 15.8 & $15^{\circ}$ \\
4 & NUP314R & 13 & 22 & - \\
5 & - & 15 & 18 & - \\
\hline
\end{tabular}

\section{Conclusion}

The finite element method and the lumped parameter method are used to establish the dynamic model of the bearing, the dynamic model of the shaft element and the meshing dynamic model of the gear pair. Based on the idea of finite element modeling, the mass matrix, stiffness matrix and damping matrix of the equations of the three models are assembled. The dynamic equations of the gear system in the third shift are established and solved.

\section{Acknowledgement}

This work was supported by International S\&T Cooperation Program of China (Grant No. 2014DFA71790), the Key Scientific and Technological Project of Jilin Province (Grant No. 20160519008JH ), Chinese National Natural Science Foundation(Grant No. 51575220) and Graduate Innovation Fund of Jilin University（Grant No. 2016170）. 


\section{References}

[1] Ajmi M, Velex P. A model for simulating the quasi-static and dynamic behaviour of solid wide-faced spur and helical gears [J]. Mechanism and Machine Theory, 2005, 40(2): 173-190.

[2] Chang L. Dynamic modeling method of parallel shaft gear transmission system and study on the law of dynamic excitation, Northwestern Polytechnical University, 2014.

[3] Kubur M, Kahraman A, Zini D M, et al. Dynamic analysis of a multi-shaft helical gear transmission by finite elements: model and experiment [J]. Journal of vibration and acoustics, 2004, 126(3): 398-406.

[4] MATLAB Finite element structural dynamic analysis and engineering application, Tsinghua University Press, 2009.

[5] Liu H. Determination of Rayleigh damping proportional coefficient [J]. Noise and Vibration Control,1999,06:21-22.

[6] Zhang Y, Wang Q, Ma H, et al. Dynamic analysis of three-dimensional helical geared rotor system with geometric eccentricity [J]. Journal of Mechanical Science and Technology, 2013, 27(11): 3231-3242. 